\title{
Nebulized in-line endotracheal dornase alfa and albuterol administered to mechanically ventilated COVID-19 patients: a case series
}

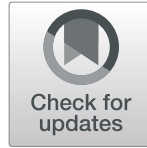

\author{
Andrew G. Weber ${ }^{1}$, Alice S. Chau², Mikala Egeblad ${ }^{3^{*}}$, Betsy J. Barnes ${ }^{4^{*}}$ (DD and Tobias Janowitz ${ }^{3,5}$
}

\begin{abstract}
Background: Mechanically ventilated patients with COVID-19 have a mortality of $24-53 \%$, in part due to distal mucopurulent secretions interfering with ventilation. DNA from neutrophil extracellular traps (NETs) contribute to the viscosity of mucopurulent secretions and NETs are found in the serum of COVID-19 patients. Dornase alfa is recombinant human DNase 1 and is used to digest DNA in mucoid sputum. Here, we report a single-center case series where dornase alfa was co-administered with albuterol through an in-line nebulizer system.
\end{abstract}

Methods: Demographic and clinical data were collected from the electronic medical records of five mechanically ventilated patients with COVID-19-including three requiring veno-venous extracorporeal membrane oxygenation - treated with nebulized in-line endotracheal dornase alfa and albuterol, between March 31 and April 24, 2020. Data on tolerability and response were analyzed.

Results: The fraction of inspired oxygen requirements was reduced for all five patients after initiating dornase alfa administration. All patients were successfully extubated, discharged from hospital and remain alive. No drugassociated toxicities were identified.

Conclusions: Results suggest that dornase alfa will be well-tolerated by patients with severe COVID-19. Clinical trials are required to formally test the dosing, safety, and efficacy of dornase alfa in COVID-19, and several have been recently registered.

Keywords: SARS-CoV-2, COVID-19, Coronavirus, Mucopurulent secretions, Dornase alfa, Neutrophil extracellular traps, ARDS, W-ECMO

\section{Background}

Critically ill patients with coronavirus disease 2019 (COVID-19), caused by the severe acute respiratory syndrome coronavirus 2 (SARS-CoV-2), progress to hypoxemic and then mixed respiratory failure, secondary to acute respiratory distress syndrome (ARDS) (Marini and Gattinoni 2020; Greenland et al. 2020). Approximately

\footnotetext{
* Correspondence: egeblad@cshl.edu; bbarnes1@northwell.edu

${ }^{3}$ Cancer Center, Cold Spring Harbor Laboratory, 1 Bungtown Road, Cold Spring Harbor, NY 11724, USA

${ }^{4}$ Center for Autoimmune, Musculoskeletal and Hematopoietic Diseases, The Feinstein Institutes for Medical Research and the Departments of Molecular Medicine and Pediatrics, Donald and Barbara Zucker School of Medicine at Hofstra/Northwell, 350 Community Drive, Manhasset, NY 11030, USA Full list of author information is available at the end of the article
}

$79-88 \%$ of patients admitted to the intensive care unit (ICU) with COVID-19 require intubation and mechanical ventilation, with a mortality of $24-53 \%$ (Cummings et al. 2020; Grasselli et al. 2020; Richardson et al. 2020; Docherty et al. 2020). ARDS in COVID-19 is characterized by respiratory failure, in part attributable to distally located mucopurulent secretions.

Dornase alfa (Pulmozyme ${ }^{\circ}$ ) is recombinant human DNase 1 and a safe mucolytic that is administered in nebulized form. It is FDA-approved in combination with standard therapies for patients with cystic fibrosis to improve sputum clearance and pulmonary function (Yang and Montgomery 2018). It is also used off-label as a mucolytic in other diseases, including ARDS (Morris and

(c) The Author(s). 2020 Open Access This article is licensed under a Creative Commons Attribution 4.0 International License, which permits use, sharing, adaptation, distribution and reproduction in any medium or format, as long as you give appropriate credit to the original author(s) and the source, provide a link to the Creative Commons licence, and indicate if changes were made. The images or other third party material in this article are included in the article's Creative Commons licence, unless indicated otherwise in a credit line to the material. If material is not included in the article's Creative Commons licence and your intended use is not permitted by statutory regulation or exceeds the permitted use, you will need to obtain permission directly from the copyright holder. To view a copy of this licence, visit http://creativecommons.org/licenses/by/4.0/. 
Mullan 2004; ClinicalTrials.gov [Internet] 2019). A mechanism by which dornase alfa might improve ventilation is by reducing the DNA-mediated viscosity of neutrophil-rich secretions (Papayannopoulos et al. 2011). There are multiple sources for the DNA in mucoid sputum, one of which is neutrophil extracellular traps (NETs). Recently, we collaboratively reported that in the discarded serum of patients with COVID-19, the levels of NETs were increased and correlated with lactate dehydrogenase $(\mathrm{LDH}), \mathrm{D}$-dimer, and C-reactive protein (CRP) levels (Zuo et al. 2020). Subsequently, NETcontaining microthrombi and increased neutrophilplatelet infiltration in pulmonary autopsies from COVID-19 patients was reported (Becker 2020; Fox et al. 2020; Middleton et al. 2020; Schonrich et al. 2020; Tay et al. 2020; Varga et al. 2020; Leppkes et al. 2020). Notably, targeting NETs reduces mortality in animal models of acute lung injury (Barnes et al. 2020; Adrover et al. 2020; Caudrillier et al. 2012; Lefrancais et al. 2018; Thomas et al. 2012). Despite recognition that mucolytic treatment may be beneficial for patients with COVID-19 (12, (Earhart et al. 2020), administration of nebulized medications, such as dornase alfa, have been limited due to risk of viral aerosolization. If risk of viral aerosolization can be avoided, dornase alfa may benefit patients with severe COVID-19 by acting as a mucolytic and by reducing NET levels in the lungs, thereby improving oxygenation and ventilation. We report the clinical course, safety, and outcomes after nebulized in-line endotracheal dornase alfa treatment for five intubated and mechanically ventilated patients with PCRconfirmed COVID-19.

\section{Methods}

The Northwell Health institutional review board that focuses on COVID-19 research approved this case series as minimal-risk research using de-identified data from routine clinical practice. Data were collected from the enterprise health record (Sunrise Clinical Manager; Allscripts) reporting database, and included patient demographics, comorbidities, inpatient medications, laboratory studies, treatment, and outcomes. We further obtained longitudinal values of the fraction of inspired oxygen $\left(\mathrm{FiO}_{2}\right)$ and of the arterial partial pressure of carbon dioxide $\left(\mathrm{PaCO}_{2}\right)$ as measures of respiratory function during treatment. Lung mechanics were assessed by obtaining mechanical power of the respiratory system (MP) and mean airway pressure (Paw). $\mathrm{FiO}_{2}$ values of the circuit were reported for those patients who required veno-venous extracorporeal membrane oxygenation (VVECMO). Ferritin, CRP, LDH, and D-dimer were obtained as measures of systemic disease and inflammation. Not all patients had laboratory investigations on the same days in relation to the nebulized and co-administered dornase alfa and albuterol $(\mathrm{nDA}+\mathrm{A})$ treatment. In the following case synopses, each measurement is therefore followed by the day in relation to the first day of treatment with $\mathrm{nDA}+\mathrm{A}$ (e.g., $\mathrm{d}$ 2 for the second day of treatment with $\mathrm{nDA}+\mathrm{A}$ or $\mathrm{d}-1$ for the day before $\mathrm{nDA}+\mathrm{A}$ treatment was initiated). Relevant nDA toxicities (hoarseness, rash, hypersensitivity reactions and hemoptysis) were clinically monitored. Hoarseness was assessed post-intubation. Rash was assessed daily via physical exam. Hypersensitivity reactions were determined via physical exam, vital signs, and vasopressor requirements. Hemoptysis was assessed in intubated patients by endotracheal tube visual inspection.

\section{Results}

Five patients treated with dornase alfa between March 31, 2020 and April 24, 2020 were identified. These patients had met the Berlin criteria for ARDS and were treated with ventilator strategies guided by the ARDS Net protocol at North Shore University Hospital within Northwell Health (Durante et al. 2002). These patients had been treated with dornase alfa because they required high levels of $\mathrm{FiO}_{2}$ and had elevated ventilation demands. All patients received the same treatment doses: nebulized dornase alfa $(2.5 \mathrm{mg})$ co-administered twice daily with the short-acting $\beta_{2}$-agonist albuterol $(2.5 \mathrm{mg})$ to improve delivery to the alveoli (referred to as $\mathrm{nDA}+$ A). Of note, $\beta_{2}$-adrenoreceptor agonism may also inhibit NET formation by direct action on neutrophils (Marino et al. 2018). The treatment was administered with an Aerogen $^{\circ}$ Solo in-line nebulizer to avoid open aerosol generation, which would place staff at risk of exposure to SARS-CoV-2.

The patient characteristics are summarized in Table 1. Patients were treated with $\mathrm{nDA}+\mathrm{A}$ between 3 to 25 days. The most common characteristics of the patients included obesity $(\mathrm{BMI} \geq 30)$ and four of the patients had hypertension. Four patients received methylprednisolone dosed at $1-2 \mathrm{mg} / \mathrm{kg} /$ day. All patients were treated with full dose or prophylactic dose anticoagulation for thrombosis. All other medications that were administered during the course of hospitalization were considered standard of care (STC) at the time of treatment and are summarized in Table S1. No adverse events related to $\mathrm{nDA}+\mathrm{A}$ treatment were observed for any of the patients throughout the duration of the study. The clinical course of the five patients treated with $\mathrm{nDA}+\mathrm{A}$ is summarized in Fig. 1. Figures 2 and 3 display the longitudinal, ventilatory, and inflammatory markers for each patient.

Patient 1 is a 56 -year-old Hispanic woman who presented in respiratory distress. Her respiratory status deteriorated over $48 \mathrm{~h}$, requiring intubation and transfer to the ICU. She was treated with $\mathrm{nDA}+\mathrm{A}$ for 6 days, starting from day 10 of intubation. $\mathrm{The}^{\mathrm{FiO}} \mathrm{O}_{2}$ requirement decreased from $70 \%(\mathrm{~d}-1)$ to $30 \%$ (d 6), $\mathrm{PaCO}_{2}$ from 58 $(\mathrm{d}-1)$ to $37 \mathrm{mmHg}(\mathrm{d} 7)$, ferritin from $1803(\mathrm{~d}-1)$ to 
Table 1 Patient data from five patients with COVID-19 who received dornase alfa with albuterol March-April, 2020

\begin{tabular}{|c|c|c|c|c|c|}
\hline Patient & 1 & 2 & 3 & 4 & 5 \\
\hline \multicolumn{6}{|l|}{ Clinical Characteristics } \\
\hline Date of admission & 29 March & 4 April & 16 March & 16 March & 26 March \\
\hline Age & 56 & 34 & 65 & 31 & 34 \\
\hline Gender & $\mathrm{F}$ & M & M & M & $\mathrm{F}$ \\
\hline Ethnicity & Hispanic & White & Asian & Hispanic & Black \\
\hline BMI & 38 & 41 & 32 & 30 & 38 \\
\hline Date of ICU admission & 31 March & 4 April & 16 March & 18 March & 26 March \\
\hline \multicolumn{6}{|l|}{ Comorbidities } \\
\hline Hypertension & Yes & Yes & Yes & Yes & \\
\hline Diabetes mellitus, type 2 & Yes & & & & \\
\hline Asthma & Yes & & Yes & & Yes \\
\hline Hyperlipidemia & & Yes & & & \\
\hline Migraine & & & & & Yes \\
\hline Chronic gastritis & & & & & Yes \\
\hline \multicolumn{6}{|l|}{ ECMO } \\
\hline Date of ECMO initiation & - & 4 April & - & 27 March & 28 March \\
\hline Date of ECMO cessation & - & 16 April & - & 10 April & 20 April \\
\hline \multicolumn{6}{|c|}{ Dornase alfa $(D A)+$ albuterol $(A)$ parameters } \\
\hline \multicolumn{6}{|c|}{ Administration (DA: $2.5 \mathrm{mg}, \mathrm{A}: 2.5 \mathrm{mg}$, both twice daily using the Aerogen ${ }^{\circledast}$ Solo nebulizer) } \\
\hline Date of DA + A initiation & 9 April & 4 April & 31 March & 1 April & 31 March \\
\hline Date of $\mathrm{DA}+\mathrm{A}$ cessation & 14 April & 6 April & 8 April & 19 April & 24 April \\
\hline Toxicities & None & None & None & None & None \\
\hline \multicolumn{6}{|l|}{ Other COVID-19 treatment } \\
\hline Methylprednisolone & Yes & Yes & & Yes & Yes \\
\hline Anakinra & & Yes & & Yes & \\
\hline CytoSorb & & & & & Yes \\
\hline \multicolumn{6}{|l|}{ Anticoagulants ${ }^{a}$} \\
\hline Enoxaparin & $40 \mathrm{mg}$ BID & $120 \mathrm{mg} \mathrm{BID}$ & 40 mg BID & $100 \mathrm{mg}$ BID & $120 \mathrm{mg} \mathrm{BID}$ \\
\hline Argatroban & & Yes & & Yes & Yes \\
\hline Heparin gtt & & & Yes & & Yes \\
\hline Venous thromboembolism & None & None & None & $\begin{array}{l}\text { Right SDVT } \\
\text { Right CVT }\end{array}$ & None \\
\hline Current State & ICU discharge & ICU discharge & ICU discharge & ICU discharge & ICU discharge \\
\hline
\end{tabular}

apatients were not on simultaneous anticoagulation therapies. BMI Body mass index, ICU Intensive care unit, ECMO Extracorporeal membrane oxygenation, BID Bis in die (twice a day), gtt Guttae (intravenous drip), SDVT Soleal deep vein thrombosis, CVT Cephalic vein thrombosis

$472 \mathrm{ng} / \mathrm{mL}(\mathrm{d} 6)$, and D-dimer from $1619(\mathrm{~d}-1)$ to 563 $\mathrm{ng} / \mathrm{mL}$ (d 6). MP had increased from $16.48(\mathrm{~d}-1)$ to $20.91 \mathrm{~J} /$ minute (d 6), and Paw from $12(\mathrm{~d}-1)$ to 20 $\mathrm{cmH}_{2} \mathrm{O}$ (d 6). Minimal changes were noted in CRP and LDH. The patient underwent a tracheostomy after 23 days of endotracheal intubation and was able to be decannulated 19 days later. She was discharged to a rehabilitation facility after a total hospital stay of 82 days.

Patient 2 is a 34-year-old white man who presented to the hospital in diabetic ketoacidosis without prior history of diabetes mellitus. He was intubated on admission and initiated on VV-ECMO. He received $\mathrm{nDA}+\mathrm{A}$ for 3 days and was de-cannulated after 12 days. No change in ECMO settings occurred during treatment time. The $\mathrm{FiO}_{2}$ requirement decreased from $100 \%$ (d 0) to $80 \%$ (d 3), MP from 36.38 (d 0) to $12.03 \mathrm{~J} / \mathrm{min}$ (d 3), Paw from 36.38 (d 0) to $12.03 \mathrm{cmH}_{2} \mathrm{O}$ (d 3), CRP from 14.14 (d 0) to $2.41 \mathrm{mg} / \mathrm{dL}$ (d 3), ferritin from 12,281 (d 0) to 5453 $\mathrm{ng} / \mathrm{mL}$ (d 3), and D-dimer from 5210 (d 0) to $2099 \mathrm{ng} /$ $\mathrm{mL}$ (d 3). Minimal changes were noted in $\mathrm{PaCO}_{2}$ and 


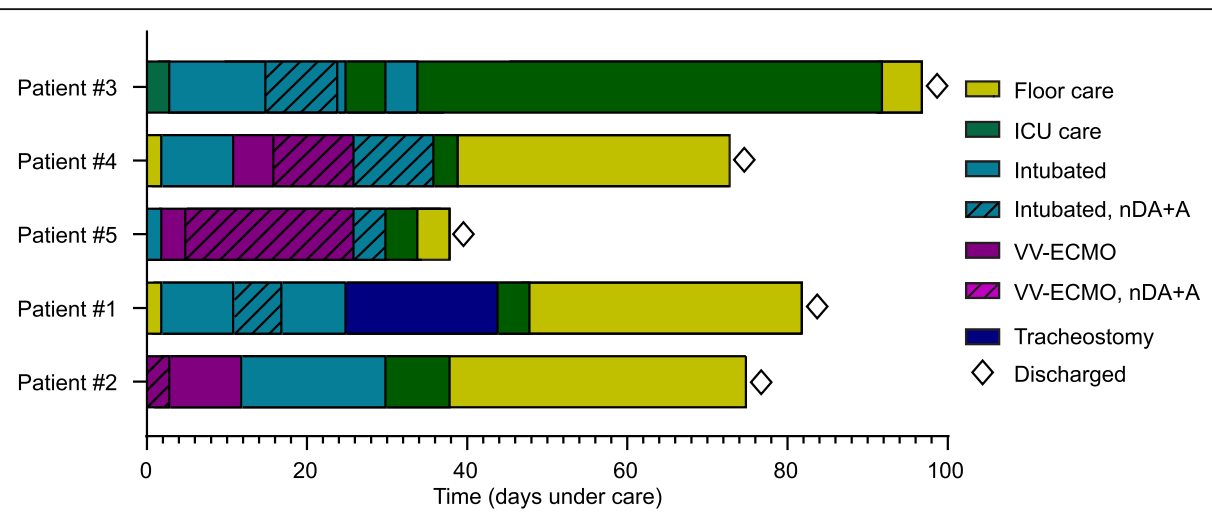

Fig. 1 Overview of the clinical course of five patients treated with nebulized dornase alfa + albuterol $(n D A+A)$

$\mathrm{LDH}$. The patient was able to be extubated after 30 days of endotracheal intubation (VV-ECMO the first 12 days). He was discharged to a rehabilitation facility after a total hospital stay of 75 days.

Patient 3 is a 65-year-old Asian man who was admitted directly to the ICU for respiratory distress and intubated 3 days later. Twelve days after intubation, he was started on 9 days of $\mathrm{nDA}+\mathrm{A}$ treatment. The $\mathrm{FiO}_{2}$ requirement decreased from $50 \%(\mathrm{~d}-1)$ to $40 \%$ (d 7), $\mathrm{PaCO}_{2}$ from 55 (d 0) to $43 \mathrm{mmHg}(\mathrm{d} \mathrm{6}$ ), and CRP from 22.07 (d 0) to $26.48 \mathrm{mg} / \mathrm{dL}$ (d 6). Minimal changes were noted in MP, Paw, ferritin, LDH, and D-dimer. He was extubated 1 day after the completion of the $\mathrm{nDA}+\mathrm{A}$ course. Five days later, he was re-intubated for an additional 4 days due to mental status changes and failure to protect his airway. The patient was extubated in ICU care 30 days after his initial endotracheal intubation. $\mathrm{He}$ subsequently developed a right colonic and small bowel perforation requiring the placement of multiple drains. He required the initiation of total parenteral nutrition until he was able to tolerate enteral feeds. Surgery was never required. He was discharged to a rehabilitation facility after a total hospital stay of 97 days.

Patient 4 is a 31-year-old Hispanic man who was intubated and transferred to the ICU from the Internal Medicine service 2 days after presenting with respiratory

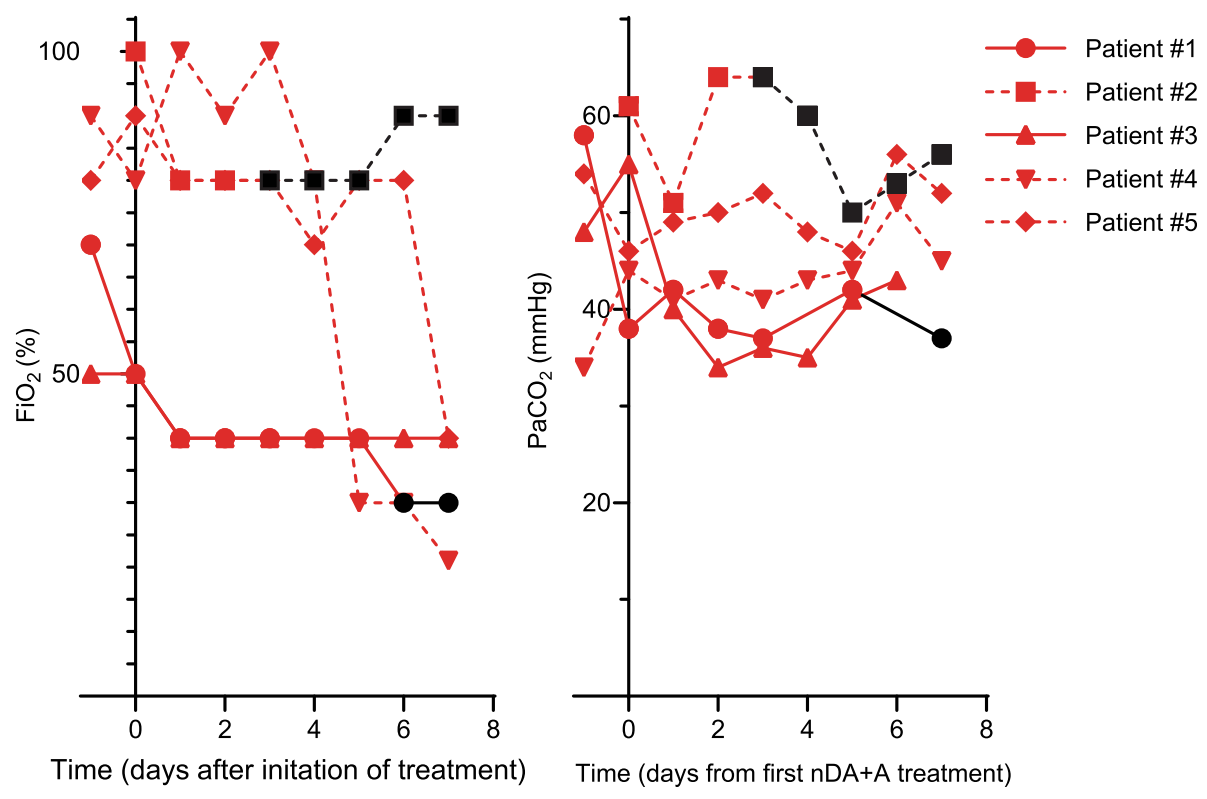

Fig. 2 Patient-level data of respiratory function during treatment with nebulized dornase alfa + albuterol $(n D A+A)$. Values were extracted from the medical records the day before and up to the seven days after the initiation of treatment. Values are graphed in black for patients after they ceased nDA + A treatment. Dashed lines indicate patients on W-ECMO. Not all markers were measured daily for every patient. FiO $\mathrm{F}_{2}$ fraction of inspired oxygen; $\mathrm{PaCO}_{2}$ : partial pressure of carbon dioxide 


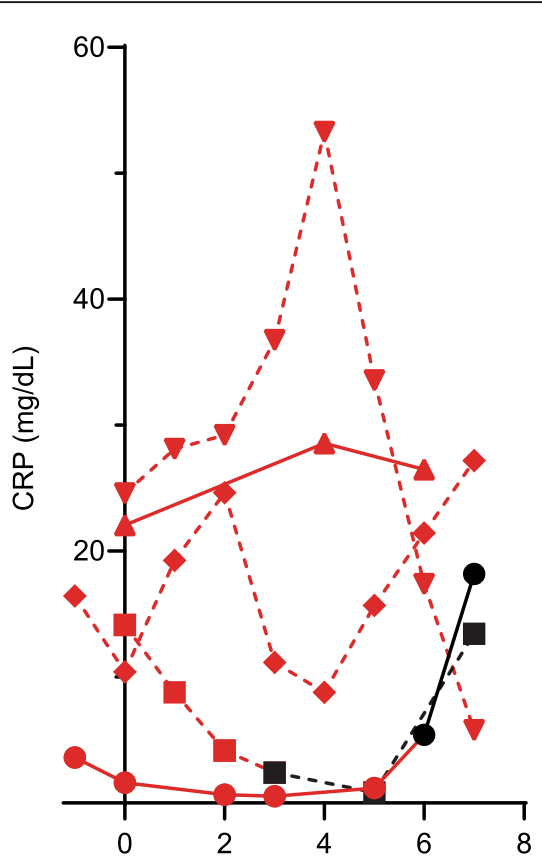

Time (days from first $\mathrm{nDA}+\mathrm{A}$ treatment)
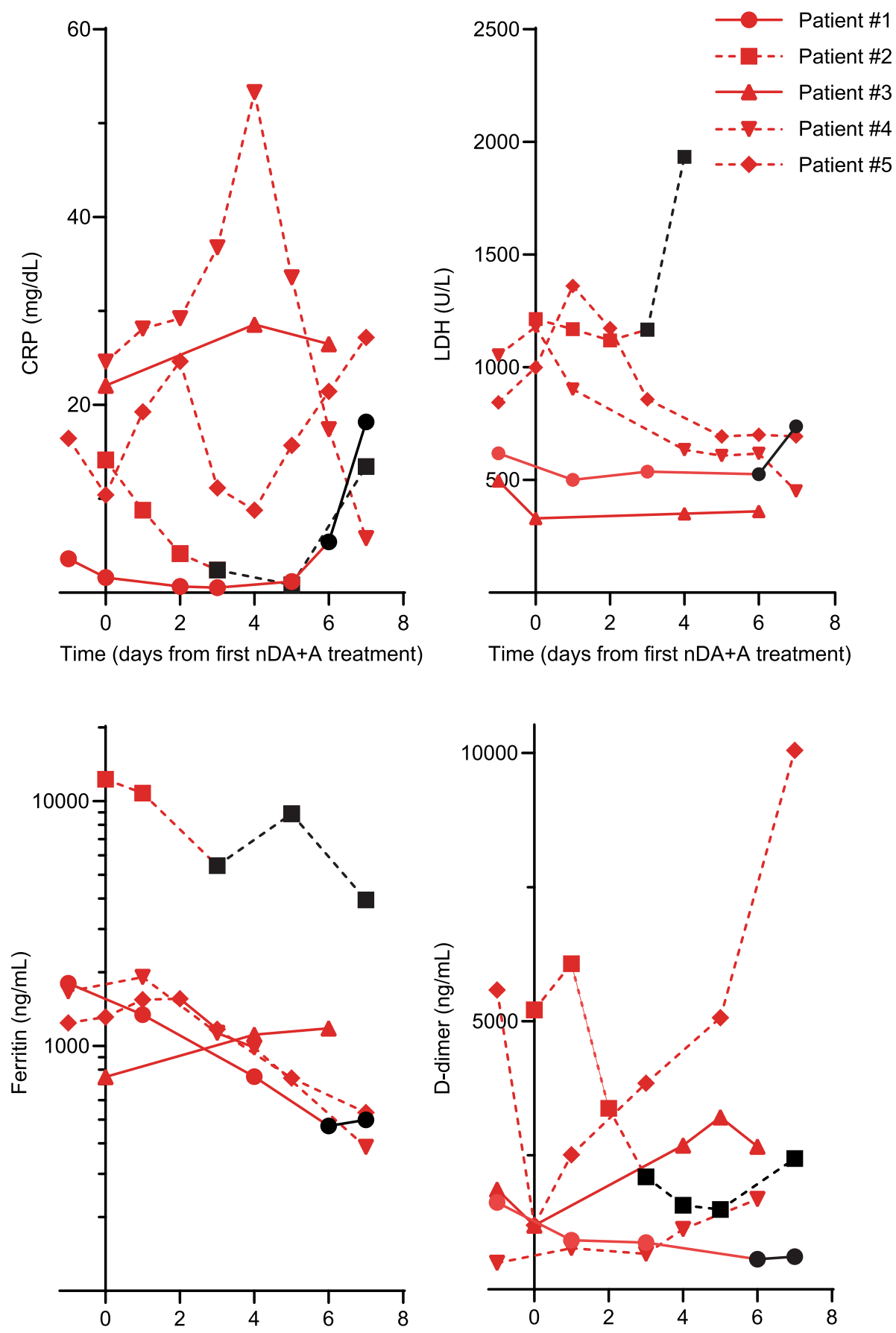

Time (days from first nDA+A treatment)

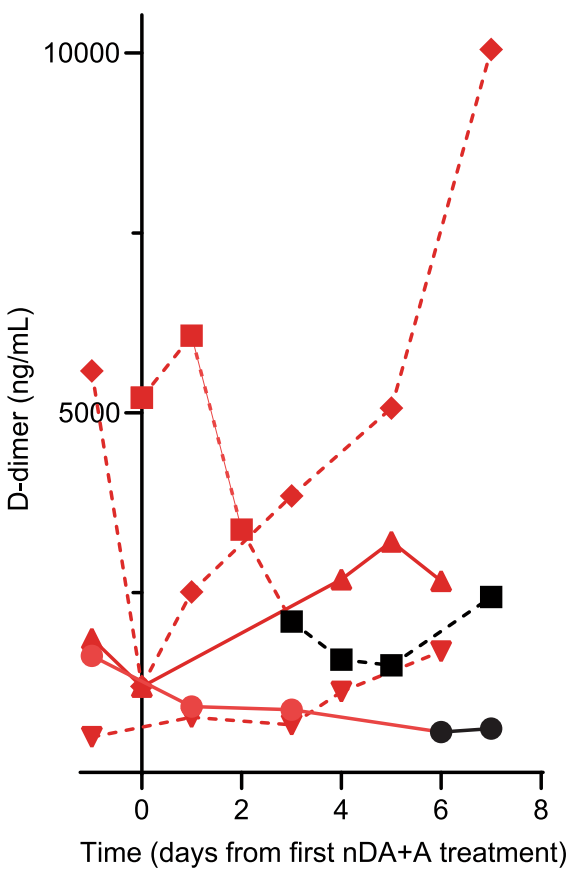

Fig. 3 Patient-level data of systemic disease during treatment with nebulized dornase alfa + albuterol $(n D A+A)$. Values were extracted from the medical records the day before and up to the seven days after the initiation of treatment. Values are graphed in black for patients after they ceased $\mathrm{nDA}+\mathrm{A}$ treatment. Dashed lines indicate patients on W-ECMO. Not all markers were measured daily for every patient. CRP: C-reactive protein; LDH: lactate dehydrogenase

distress. Nine days after intubation, he was initiated on VV-ECMO. Five days after cannulation, he was started on the $\mathrm{nDA}+\mathrm{A}$ treatment. After ten days, he was decannulated and remained intubated for ten days while continuing the $\mathrm{nDA}+\mathrm{A}$ treatment. No change in ECMO settings occurred during treatment time. He was then extubated and discharged to the floor. $\mathrm{The}^{\mathrm{FiO}}{ }_{2}$ requirement decreased from $90 \%(\mathrm{~d}-1)$ to $21 \%(\mathrm{~d} 7)$, Paw from $19(\mathrm{~d}-1)$ to $16 \mathrm{cmH}_{2} \mathrm{O}(\mathrm{d} 7)$, and $\mathrm{LDH}$ from $1054(\mathrm{~d}-$ 1) to $451 \mathrm{U} / \mathrm{L}$ (d 7). Ferritin initially decreased from 
$1669(\mathrm{~d}-1)$ to $387 \mathrm{ng} / \mathrm{mL}(\mathrm{d} 7)$. On day 15 of treatment, he developed methicillin-resistant Staphylococcus aureus (MRSA) pneumonia and bacteremia. Ferritin thus increased to $1619 \mathrm{ng} / \mathrm{mL}$ (d 13) prior to decreasing to 555 $\mathrm{ng} / \mathrm{mL}$ (d 19) with antibiotic treatment. Minimal changes were noted in $\mathrm{MP}, \mathrm{PaCO}_{2}, \mathrm{CRP}$, and D-dimer. He was transferred to an acute inpatient rehabilitation facility after a total hospital stay of 73 days.

Patient 5 is a 34-year-old black woman who was intubated at an outside hospital, then transferred to the North Shore University Hospital ICU. Two days later, she was cannulated for VV-ECMO. She required VVECMO for 24 days and was intubated for a total of 30 days. She was treated with $\mathrm{nDA}+\mathrm{A}$ for 25 days starting on day 4 following cannulation for VV-ECMO. While on VV-ECMO for the first 5 days, CytoSorb therapy was applied. She was de-cannulated after 24 days, extubated after 4 days, and discharged to the floor. No change in ECMO settings occurred during treatment time. The $\mathrm{FiO}_{2}$ requirement fell from $80 \%(\mathrm{~d}-1)$ to $40 \%(\mathrm{~d} 7)$, ferritin from $1244(\mathrm{~d}-1)$ to $535 \mathrm{ng} / \mathrm{mL}(\mathrm{d} 7)$, and $\mathrm{LDH}$ from $844(\mathrm{~d}-1)$ to $693 \mathrm{U} / \mathrm{L}(\mathrm{d} 7)$. MP increased from $11.03(\mathrm{~d}-1)$ to $20.08 \mathrm{~J} /$ minute $(\mathrm{d} 7)$, Paw from $15(\mathrm{~d}-1)$ to $22 \mathrm{cmH}_{2} \mathrm{O}$ (d 7). Minimal changes were noted in $\mathrm{PaCO}_{2}, \mathrm{CRP}$, and D-dimer. She declined rehabilitation therapy and was discharged home after a total hospital stay of 38 days.

\section{Discussion}

At the doses utilized, no $\mathrm{nDA}+\mathrm{A}$ treatment-associated toxicities were identified. $\mathrm{FiO}_{2}$ requirements decreased for all five patients 7 days after $\mathrm{nDA}+\mathrm{A}$ treatment was initiated, while measures of lung mechanics varied. All patients were discharged from the hospital and remain alive at the time of submission of this report. During the time period that these patients were treated, $\sim 25 \%$ mortality was reported during the first month for patients requiring ICU care within our hospital system (Richardson et al. 2020). We recognize that changes in $\mathrm{FiO}_{2}$ levels, lung mechanics, and systemic inflammatory markers may be independent of the $\mathrm{nDA}+\mathrm{A}$ treatment. Clinical trials are therefore required to test the dose range, safety, and efficacy of dornase alfa in patients with COVID-19 in this setting and possibly earlier in the disease course. Endpoints should include measurements of the effect on respiratory function and mechanics, as well as on systemic inflammation, coagulopathy, secondary infections, and the presence of NETs in plasma. Eight such trials were recently registered (NCT04359654, NCT04355364, NCT04432987, NCT04409925, NCT04 445285, NCT04402944, NCT04402970, NCT0445 9325).

Although it is not yet clear whether nebulized dornase alfa will have any effect on blood NET levels or systemic inflammation in COVID-19, a reduction in systemic inflammatory markers has been reported after use of dornase alfa in patients with cystic fibrosis (Yang and Montgomery 2018). We did note a reduction in CRP in two patients (patients 2 and 3 ) and a reduction in Ddimer in two patients (patients 1 and 2) during $\mathrm{nDA}+\mathrm{A}$ treatment. LDH was reduced for the patients on VVECMO during $\mathrm{nDA}+\mathrm{A}$ treatment, and ferritin was reduced in four out of five patients. Due to the small sample size and the common occurrence of secondary infections in ventilated patients with COVID-19, we are unable to comment on any potential relationship between $\mathrm{nDA}+\mathrm{A}$ administration and the risk of secondary infections.

\section{Conclusions}

This case report suggests that nebulized dornase alfa in combination with albuterol is a safe treatment option, supporting randomized, controlled clinical trials for mechanically ventilated patients with ARDS secondary to COVID-19, including for those on VV-ECMO-a patient population with an urgent, unmet need for effective therapies.

\section{Supplementary information}

Supplementary information accompanies this paper at https://doi.org/10. 1186/s10020-020-00215-w.

Additional file 1 Supplemental Table 1. Additional medications that dornase alfa+albuterol-treated COVID-19 patients received while in the hospital.

\section{Abbreviations \\ ARDS: Acute respiratory distress syndrome; BID: Bis in die (twice daily); COVID-19: Coronavirus disease 2019; CRP: C-reactive protein; d: Day; $\mathrm{FiO}_{2}$ : Fraction of inspired oxygen; gtt: Guttae (intravenous drip); ICU: Intensive care unit; LDH: Lactate dehydrogenase; MRSA: Methicillin- resistant Staphylococcus aureus; nDA + A: Nebulized dornase alfa plus albuterol; NETs: Neutrophil extracellular traps; $\mathrm{PaCO}_{2}$ : Arterial partial pressure of carbon dioxide; SARS-CoV-19: Severe acute respiratory syndrome coronavirus 2; W-ECMO: Veno-venous extracorporeal membrane oxygenation}

\section{Acknowledgements}

The authors thanks "The NETwork to Target Neutrophils in COVID-19," Eric Gottesman, William Taylor, David Menon, and David Tuveson for helpful discussions, as well as the Northwell COVID-19 Research Consortium for facilitating the study.

\section{Disclaimer}

The initial characteristics of 5700 patients from Northwell Health are presented elsewhere (Richardson et al. 2020). This case series presented indepth results on the clinical status of five patients treated with dornase alfa that were not presented in that article.

\section{Authors' contributions}

Concept and design, analysis and interpretation of data, and drafting of the manuscript: A.G.W., A.S.C., M.E., B.J.B., and T.J. Data acquisition: A.G.W. and B.J.B. The authors read and approved the final manuscript.

Authors' information Not applicable. 


\section{Funding}

This work was supported by the William C. and Joyce C. O'Neil Charitable Trust. In addition, M.E. and T.J. are supported by NIH grant 5P30CA045508-30. B.J.B. is supported by NIH grant 1R01AR076242-01 and DOD LRP W81XWH-18-1-0674. A.S.C. was supported by The Primary Immune Deficiency Treatment Consortium (U54 Al 082973), funded jointly by the National Center for Advancing Translational Sciences (NCATS) and the National Institute of Allergy and Infectious Diseases (NIAID). The funding bodies had no role in the design of the study, in collection, analysis, and interpretation of data, or in writing the manuscript.

\section{Availability of data and materials}

All data generated or analyzed during this study are included within the article.

\section{Ethics approval and consent to participate}

The Northwell Health institutional review board that focuses on COVID-19 research approved this case series as minimal-risk research using de-identified data from routine clinical practice. Informed consent to participate in the study was obtained from the participants or their health care proxies. The study has been registered as "Dornase Alfa Administered to Patients With COVID-19 (DACOVID)" at ClinicalTrials.gov with ClinicalTrials.gov Identifier: NCT04387786.

\section{Consent for publication}

Not applicable.

\section{Competing interests}

Mikala Egeblad is receiving lonodelestat from Santhera for preclinical studies, but has no financial relationship with Santhera. The other authors declare that they have no competing interests.

\section{Author details}

${ }^{1}$ Division of Pulmonary, Critical Care, and Sleep Medicine, Department of Medicine, Northwell Health, 300 Community Drive, Manhasset, NY 11030, USA. ${ }^{2}$ Division of Allergy and Infectious Diseases, Department of Medicine, University of Washington and the Center for Immunity and Immunotherapies, Seattle Children's Research Institute, 1900 9th Ave, Seattle, WA 98101, USA. ${ }^{3}$ Cancer Center, Cold Spring Harbor Laboratory, 1 Bungtown Road, Cold Spring Harbor, NY 11724, USA. ${ }^{4}$ Center for Autoimmune, Musculoskeletal and Hematopoietic Diseases, The Feinstein Institutes for Medical Research and the Departments of Molecular Medicine and Pediatrics, Donald and Barbara Zucker School of Medicine at Hofstra/ Northwell, 350 Community Drive, Manhasset, NY 11030, USA. ${ }^{5}$ Northwell Health Cancer Institute, 450 Lakeville Road, New Hyde Park, NY 11042, USA.

Received: 1 June 2020 Accepted: 7 September 2020

\section{Published online: 29 September 2020}

\section{References}

Adrover JM, Aroca-Crevillen A, Crainiciuc G, Ostos F, Rojas-Vega Y, Rubio-Ponce A, et al. Programmed 'disarming' of the neutrophil proteome reduces the magnitude of inflammation. Nat Immunol. 2020;21(2):135-44.

Barnes BJ, Adrover JM, Baxter-Stoltzfus A, Borczuk A, Cools-Lartigue J, Crawford $J M$, et al. Targeting potential drivers of COVID-19: neutrophil extracellular traps. J Exp Med. 2020;217(6):e20200652.

Becker RC. COVID-19 update: Covid-19-associated coagulopathy. J Thromb Thrombolysis. 2020;50(1):54-67.

Caudrillier A, Kessenbrock K, Gilliss BM, Nguyen JX, Marques MB, Monestier M, et al. Platelets induce neutrophil extracellular traps in transfusion-related acute lung injury. J Clin Invest. 2012;122(7):2661-71.

ClinicalTrials.gov [Internet]. Identifier NCT03368092, inhaled Dornase alpha to reduce respiratory failure after severe trauma (TRAUMADORNASE). Bethesda: National Library of Medicine (US); 2019. 2017 Dec 11. [cited 2020 Apr 28]. Available from: https://clinicaltrials.gov/ct2/show/NCT03368092.

Cummings MJ, Baldwin MR, Abrams D, Jacobson SD, Meyer BJ, Balough EM, et al. Epidemiology, clinical course, and outcomes of critically ill adults with COVID-19 in new York City: a prospective cohort study. Lancet. 2020; 395(10239):1763-70.

Docherty AB, Harrison EM, Hardwick HE, Holden KA, Dondelinger F, Mersen $L$, et al. Features of 20,133 UK patients in hospital with COVID-19 using the ISARIC WHO clinical characterisation protocol: prospective observational cohort study. BMJ. 2020;369:m1985.
Durante G, Turco M, Rustichini L, Cosimini P, Giunta F, Hudson LD, et al. ARDSNet lower tidal volume Ventilatory strategy may generate intrinsic positive endexpiratory pressure in patients with acute respiratory distress syndrome. Am J Respir Crit Care Med. 2002;165(9):1271-4.

Earhart AP, Holliday ZM, Hofmann HV, Schrum AG. Consideration of dornase alfa for the treatment of severe COVID-19 acute respiratory distress syndrome. New Microbes New Infect. 2020;35:100689.

Fox SE, Akmatbekov A, Harbert JL, Li G, Quincy Brown J, Vander Heide RS. Pulmonary and cardiac pathology in African American patients with COVID19: an autopsy series from New Orleans. Lancet Respir Med. 2020;8(7):681-6.

Grasselli G, Zangrillo A, Zanella A, Antonelli M, Cabrini L, Castelli A, et al. Baseline characteristics and outcomes of 1591 patients infected with SARS-CoV-2 admitted to ICUs of the Lombardy region, Italy. Jama. 2020;323(16):1574-81.

Greenland JR, Michelow MD, Wang L, London MJ. COVID-19 infection: implications for perioperative and critical care physicians. Anesthesiology. 2020;132(6):1346-61.

Lefrancais E, Mallavia B, Zhuo H, Calfee CS, Looney MR. Maladaptive role of neutrophil extracellular traps in pathogen-induced lung injury. JCl Insight. 2018:3(3):e98178.

Leppkes M, Knopf J, Naschberger E, Lindemann A, Singh J, Herrmann I, et al. Vascular occlusion by neutrophil extracellular traps in COVID-19. EBioMedicine. 2020;58:102925.

Marini JJ, Gattinoni L. Management of COVID-19 respiratory distress. JAMA. 2020; 323(22):2329-30

Marino F, Scanzano A, Pulze L, Pinoli M, Rasini E, Luini A, et al. beta2 -Adrenoceptors inhibit neutrophil extracellular traps in human polymorphonuclear leukocytes. J Leukoc Biol. 2018;104(3):603-14.

Middleton EA, He XY, Denorme F, Campbell RA, Ng D, Salvatore SP, et al. Neutrophil extracellular traps (NETs) contribute to Immunothrombosis in COVID-19 acute respiratory distress syndrome. Blood. 2020;136(10):1169-79.

Morris C, Mullan B. Use of dornase alfa in the management of ARDS. Anaesthesia. 2004;59(12):1249.

Papayannopoulos V, Staab D, Zychlinsky A. Neutrophil Elastase enhances sputum Solubilization in cystic fibrosis patients receiving DNase therapy. PLoS One. 2011;6(12):e28526.

Richardson S, Hirsch JS, Narasimhan M, Crawford JM, McGinn T, Davidson KW, et al. Presenting characteristics, comorbidities, and outcomes among 5700 patients hospitalized with COVID-19 in the new York City area. Jama. 2020; 323(20):2052-9.

Schonrich G, Raftery MJ, Samstag Y. Devilishly radical NETwork in COVID-19: oxidative stress, neutrophil extracellular traps (NETs), and T cell suppression. Adv Biol Regul. 2020;77:100741.

Tay MZ, Poh CM, Renia L, MacAry PA, Ng LFP. The trinity of COVID-19: immunity, inflammation and intervention. Nat Rev Immunol. 2020;20(6):363-74.

Thomas GM, Carbo C, Curtis BR, Martinod K, Mazo IB, Schatzberg D, et al. Extracellular DNA traps are associated with the pathogenesis of TRALI in humans and mice. Blood. 2012;119(26):6335-43.

Varga Z, Flammer AJ, Steiger P, Haberecker M, Andermatt R, Zinkernagel AS, et al. Endothelial cell infection and endotheliitis in COVID-19. Lancet. 2020; 395(10234):1417-8.

Yang C, Montgomery M. Dornase alfa for cystic fibrosis. Cochrane Database Syst Rev. 2018;9:Cd001127.

Zuo Y, Yalavarthi S, Shi H, Gockman K, Zuo M, Madison JA, et al. Neutrophil extracellular traps in COVID-19. JCI Insight. 2020;5(11):e138999.

\section{Publisher's Note}

Springer Nature remains neutral with regard to jurisdictional claims in published maps and institutional affiliations. 